\title{
Prostituição e atividades ilícitas entre travestis de baixa renda ${ }^{1}$
}

\author{
Marcos Roberto Vieira Garcia ${ }^{2}$ \\ Universidade de São Paulo
}

\begin{abstract}
Este artigo analisa a influência da prostituição e das atividades ilícitas na formação da identidade entre travestis de baixa renda. Na primeira parte é discutida sua relação com os clientes, que mostra a incorporação de fragmentos das identidades da "puta" e a do "malandro" por elas. Na segunda, as atividades ilegais realizadas são vistas como fruto de dificuldades econômicas e do abuso de drogas, mas também como conseqüência do processo de incriminação a que foram historicamente submetidas, o que as leva a assimilar parcialmente a identidade do "bandido" em sua "colcha de retalhos" identitária.

Palavras-chave: Travestis, Violência, Prostituição, Criminalidade.
\end{abstract}

Prostitution and illegal activities among low-income travestis

This article analyses the influence of prostitution and illegal activities in the formation of identity among low income travesties. In the first part, we discuss their relationship with clients, showing the assimilation of two different identities by them: the "puta" ["whore"] and the "malandro" ["rogue"]. In the second, we propose that the illegal activities that travestis take part are related to economic difficulties and drug abuse, but also are consequences of the social incrimination process directed to them in Brazil, which make them assimilate fragments of the "bandido" ["bandit"] identity in their "patchwork" one.

Keywords: Travestis, Violence, Prostitution, Criminality.

\section{Introdução}

$\mathrm{O}$ estudos sobre travestis realizados no Brasil sempre enfatizaram a questão da construção de gênero entre elas. Tal interesse é semelhante ao existente em outros países, com relação a outras identidades transgenéricas. As travestis, da mesma forma que transformistas, crossdressers, drag-queens e outros, ao desafiarem a idéia de que o gênero seria uma decorrência natural das características físicas ou biológicas de homens e mulheres, acabam por suscitar a atenção dos estudos acadêmicos que buscam mostrar como o gênero é socialmente construído. Uma consideração a ser feita com relação a esta ênfase, contudo, é a de que a mesma pode prejudicar a percepção de que há outras esferas relevantes na compreensão destas identidades, por vezes relegadas a um segundo plano.

Buscamos, no presente artigo, apresentar alguns aspectos relacionados à prostituição e às atividades ilícitas entre travestis de baixa renda, com o intuito de ampliar o conhecimento sobre este segmento, mas também buscando demonstrar como as questões relativas ao gênero entre elas se articulam a outras, formando uma constelação bastante particular. As travestis aqui analisadas fizeram parte de um trabalho de promoção de saúde, que durou quatro anos e se realizou por meio de encontros que ocorriam em uma instituição da rede estadual de saúde, na região central de São Paulo. Nestes, eram constantemente discutidas questões relacionadas ao

1 Agradeço aos professores Ivette Lehman, Vera Paiva, Sérgio Adorno, Marília Carvalho e Geraldo Paiva pelas importantes sugestões feitas a respeito da pesquisa.

2 Mestre e doutor em psicologia social pelo Instituto de Psicologia da Universidade de São Paulo. É autor do livro Virgindade e iniciação sexual entre as adolescentes brasileiras (São Paulo: Arte \& Ciência, 2004). 
trabalho, ao cotidiano da prostituição ao (ab) uso de drogas, à hormonização e siliconização dos corpos, ao sexo-seguro, às dificuldades de relacionamento dentro do grupo, dentre outras. Os dados obtidos durante esta intervenção serviram da base para a elaboração de uma tese de doutorado junto ao Departamento de Psicologia Social e do Trabalho do Instituto de Psicologia da Universidade de São Paulo (Garcia, 2007). Nesta, as dimensões relacionadas à construção do gênero e às transformações corpóreas foram objetos de consideração detalhada, mas houve a preocupação de se ampliar o entendimento sobre este grupo pela reflexão sobre temas como o trabalho e a violência, que serão desenvolvidos no presente artigo. A constituição da identidade entre as travestis pesquisadas foi entendida como fruto da incorporação de diferentes identidades presentes na sociedade brasileira, formando uma espécie de "colcha de retalhos" identitária, sujeita a tensões e contradições entre suas partes constituintes. Foram consideradas como principais fragmentos incorporados neste processo as identidades da mulher submissa, da mulher fatal, do viado, da puta, do malandro e do bandido. O presente artigo busca desenvolver algumas contingências relacionadas à assimilação das três últimas citadas.

\section{A incorporação da "puta"}

A identidade travesti que se desenvolveu nas grandes cidades brasileiras a partir da década de 70 se diferencia claramente daquela relativa à década anterior, quando o termo "travesti" se referia principalmente às transformistas que participavam de shows que se disseminaram pelo país, como mostra Green (2000). Tal diferença está relacionada à entrada das travestis no universo da prostituição e a conseqüente ocupação das ruas e avenidas das grandes cidades.

Uma vez que a prostituição é uma posição histórica e culturalmente instituída como feminina - ainda que submetida a normas ditadas por um domínio masculino, como mostra Moraes (1996) -, consideramos que a apropriação desse campo de trabalho por parte das travestis pesquisadas as levava à incorporação da identidade da "puta" em sua "colcha de retalhos" identitária. Se algumas se identificavam como "profissionais do sexo", o que implica em uma ressignificação do sentido historicamente atribuído à prostituição, relacionado à valorização desta enquanto forma de trabalho, a maior parte parecia se apropriar de uma concepção imaginária do que é "ser puta" típica da cultura de gêneros tradicional no Brasil. Kulick (1998) observa, neste sentido, que a "puta" é a representação de mulher mais comum entre travestis de Salvador por ele estudadas.

Analisando a cultura sexual brasileira tradicional, Parker (1992, p. 85) conceitua a "puta" como uma figura que desempenha papel importante na construção do gênero da vida diária. Ao mesmo tempo em que serve de veículo de confirmação da masculinidade para seus clientes, a puta "é vista como agente de destruição, como a mulher que 'come', que desvia homens, famílias, tudo que encontra no seu caminho". Alguns estereótipos associados à puta no Brasil, apontados por Moraes (1996), como o uso de roupas marcadamente roubos e furtos sensuais e a expressão por meio de posturas e gestos considerados imorais, eram fortemente assimilados pelas travestis investigadas. A impressão que formei no contato semanal com elas foi semelhante à descrita por Welzer-Lang (1994) a respeito das transgêneros que se prostituem em Lyon, na França: a de que elas pareciam corresponder ao estereótipo da prostituta muito mais do que as mulheres que se prostituem.

A incorporação da imagem da "puta" por elas parece ser resultante de uma série de fatores: da contigüidade geográfica, que favorece o contato às vezes próximo com mulheres prostitutas, da necessidade de corresponder às fantasias de seus clientes e da necessidade de atrair o desejo dos homens, conferindo-lhes um lugar eminentemente feminino em seu 
imaginário. Entre as travestis estudadas, a prostituição aparecia, assim, não somente como motivada pela necessidade econômica, mas também como um espaço de afirmação da feminilidade, observação concordante com as realizadas por Kulick (1998) e Benedetti (2000), que vêem a prostituição como um campo de experiências prazerosas para as travestis, certamente mais do que entre a maior parte das prostitutas mulheres:

R. [uma das pouquíssimas travestis do Grupo que não se prostituíam regularmente e que tinha um pequeno salão de cabeleireira, adquirido após um período vivendo na Europa] disse que tinha um "vício" em ir para a Avenida, mesmo não precisando mais do dinheiro. Contou que adorava ver os carros pararem, buzinarem para ela, que achava aquilo "o máximo".

Isso explica também seu desprezo voltado aos clientes que buscavam por relações sexuais passivas nos "programas", uma vez que, embora isso garantisse a satisfação das necessidades financeiras, não realizava aquelas de serem desejadas como "mulheres". O "programa", contudo, quando realizado com um cliente que buscava por sexo "ativo" e que as pagava satisfatoriamente, era visto como algo agradável. De forma semelhante, a falta de clientes era motivo de queixa da parte delas, não somente pelos problemas financeiros que gerava, como também por não proporcionar seu reconhecimento como "mulheres" desejáveis. Nesse sentido, a prostituição passa a ser um dos únicos contextos onde a travesti desenvolve a auto-estima, podendo ser elogiada, reconhecida, "cantada" e, ao mesmo tempo, ganhar dinheiro, como mostra Kulick (1998). Tal consideração, contudo, deve ser relativizada em função da "decadência" no mercado sexual, fonte de sofrimento intenso para as travestis investigadas, especialmente quando não conseguiam ganhar o suficiente para manter seu modo de vida.

\section{A relação com os clientes e a assimilação do "malandro"}

A demanda por determinadas formas de relacionamento sexual por parte dos clientes determina em larga medida as configurações da prostituição. Nas palavras de Welzer-Lang (1994, p. 15), "la prostitution s'adapte à la société où elle prend corps". É em virtude, portanto, do desejo dos clientes que a prostituição travesti se organiza, fazendo destes personagens importantes em qualquer discussão que se refira ao tema. A consideração dos clientes aqui, contudo, é feita com base nas descrições que as próprias travestis pesquisadas faziam dos mesmos, uma vez que não houve a possibilidade de um contato direto com eles, ao contrário do ocorrido com alguns "maridos" (companheiros das travestis). Pelo fato da experiência de relação sexual com travestis ser algo comumente envolvido em uma atmosfera de vergonha e culpa, a abordagem de seus clientes é reconhecidamente difícil ${ }^{3}$.

A descrição feita dos clientes era heterogênea. Havia aqueles que as buscavam, segundo elas, como "mulheres", mantendo relacionamento sexual apenas "ativo", outros que procuravam por sexo "passivo" e ainda aqueles que praticavam as duas modalidades de relação. Havia ainda aqueles, minoritários, que demandavam por agressões físicas, e a procura por parte de casais, que buscavam relacionamento sexual da travesti com o homem, a mulher ou ambos. A idade dos clientes era referida também como bastante variada, embora os mais velhos predominassem. A combinação da idade mais avançada com o desejo por relacionamento sexual passivo correspondia ao cliente que denominavam "maricona", o tipo mais depreciado por elas, o que se dava tanto por sua passividade como pela idade. Como mostra Perlongher

3 O único estudo disponível sobre o tema, o de Pelúcio (2005) retrata um segmento reduzido dos mesmos - que se auto-intitulam "T-lovers". Tais clientes (que se relacionam com aquelas de segmentos de renda mais altos) parecem diferir bastante daqueles das travestis do Grupo. 
(1987), em seu estudo sobre michês de São Paulo, a idade leva a uma desvalorização no universo homoerótico, dificultando o encontro de parceiros para relações sexuais ocasionais e gerando a necessidade de se pagar pelas mesmas. Este e o fato de haver certa correlação entre idade e disponibilidade financeira explicariam, para ele, o fato de michês terem como clientes mais comuns homossexuais mais velhos. Consideramos que tal interpretação é também apropriada para o caso dos clientes das travestis aqui investigadas. Mas estas eram procuradas também, embora minoritariamente, por clientes mais jovens, denominados de "boys", bem mais agradáveis a elas, mesmo quando buscavam por relações sexuais "passivas" - casos em que eram referidos como bicha-boys.

A submissão das travestis aos desejos e necessidades dos clientes, de certa forma à prostituição, era visível no desempenho do sexo anal ativo com seus clientes. Embora a grande maioria preferisse relações sexuais passivas, o desejo dos clientes em serem penetrados acabava prevalecendo, o que fazia com que estes fossem muitas vezes objetos de escárnio dentro do Grupo, algo que denotava certa raiva pela situação vivida. A transformação do corpo também era, em certa medida, determinada pelas demandas dos clientes, como no caso da evitação da cirurgia de transgenitalização, o que impossibilitava o desempenho do sexo "ativo" com os clientes $^{4}$. Ter seios e nádegas volumosos era algo também descrito não somente como fruto da necessidade de satisfação pessoal por parte delas, mas, também, como algo comumente desejado pelos clientes.

Apesar de, em certa medida, estarem em uma posição de subserviência em relação a seus clientes, não era assim que as travestis estudadas os viam. $O$ mais comum nos discursos em referência a eles era desqualificá-los, como no caso das "mariconas". Se com os "maridos" as travestis aceitavam muitas vezes uma posição de submissão e na relação com os "vícios" (parceiros sexuais ocasionais) a relação parecia mais igualitária, na relação com os clientes pareciam buscar, na maior parte das vezes, se sentir em uma posição de domínio sobre os mesmos. Podemos pensar, assim, que, nessa relação, uma outra figura identitária é parcialmente por elas incorporada: a do malandro.

Silva (1993) refere, no início de seu estudo sobre travestis cariocas no Rio de Janeiro, ter a hipótese inicial de que a personagem travesti poderia ser entendida como uma metamorfose do malandro carioca, hipótese à qual não volta a se referir em seu trabalho. Propomos retomar essa hipótese de uma outra forma: não a de que a travesti corresponda a uma transformação do malandro, mas a de que a identidade do malandro seja parcialmente incorporada na identidade travesti.

O malandro tem sido analisado por diversos cientistas sociais no Brasil. Cândido (1993), em sua análise de "Memórias de um Sargento de Milícias", observa a proximidade do malandro com "tricksters" de outras literaturas, como os presentes nas fábulas infantis (representados por animais como a do macaco e do jabuti) e no folclore, como o personagem Pedro Malasartes. É uma figura que transita entre o universo da ordem e da desordem, não se fixando em nenhum dos dois e permanecendo em um lugar ambíguo. Em continuidade com essa análise, Da Matta (1983) faz considerações importantes a respeito de como a figura do malandro se descola da figura do bandido. Avalia, ao analisar o mito de "Pedro Malasartes", que o malandro não vive nem no mundo da ordem (do trabalho formal) nem no da desordem (da criminalidade), "vive nos seus interstícios, entre a ordem e a desordem, utilizando ambos e nutrindo-se tanto dos que estão fora quanto dos que estão dentro do mundo quadrado da estrutura" (p. 139).

Considerando especificamente a figura do malandro carioca, Zaluar (2004) observa também diferenças com a figura do bandido. O malandro, personagem da boemia carioca até meados da década de 60 , participava intensamente da vida cultural da cidade e do espaço 
público, embora fosse continuamente associado ao golpismo e à preguiça. $\mathrm{O}$ bandido, em especial aquele surgido no rastro do tráfico de drogas no Rio de Janeiro, a partir da década de 70, por outro lado, não participa deste mesmo espaço público, uma vez que não leva em consideração o "outro", em sua busca pela maximização dos lucros nos grandes mercados da contravenção e do tráfico de drogas.

Questionando tais análises, Misse (1999), ao abordar a transformação histórica do imaginário associado ao banditismo no Rio de Janeiro, considera que opor o malandro ao bandido corresponde a uma idealização do primeiro e à estigmatização do segundo. Tal visão "romântica" do malandro, criada nos anos 60, para ele, o representa como alguém avesso à violência e o associa

à recusa ao trabalho e a sua substituição por atividades ilícitas, expedientes de 'ganho' como o jogo, o furto e o estelionato ou à sua preeminência em mercados ilícitos, que exigem certos talentos e habilidades, principalmente a prostituição e o jogo, ou em situações delicadas, como nas estratégias de sedução (p. 253).

Misse (1999, p. 390) observa que tal representação pressupõe a existência de tipos sociais estanques, que se mantém por longos períodos, e mostra que as representações do malandro na primeira metade do século XX o associavam a alguém bastante perigoso, diferentemente do que passou a ocorrer nas representações posteriores. Propõe que tal figura, assim como outras associadas ao banditismo, como as do marginal, do valente e do vagabundo, seja compreendida a partir de sua historicidade e observa que tais figuras têm conotações diferentes no "mundo do crime" e nos discursos que circulam por outros setores sociais, se modificando e, por vezes, se fundindo umas às outras em seu processo de transformação.

Tomando como pertinente a crítica de Misse (1999), é importante considerar, em nosso estudo, contudo, que é justamente a figura imaginária do "malandro" que está em jogo, quando falamos de sua assimilação parcial pelas travestis. Não haveria, aliás, como pensar de outro modo, uma vez que o surgimento das travestis como segmento social (nos anos 70) é posterior à "morte" ou "aposentadoria" do "malandro", personagem que desaparece em meados dos anos 60 .

A figura do malandro é bastante presente no universo da prostituição, como mostram Misse (1999) e Moraes (1996). Esta autora mostra que o malandro aparece como uma figura mitificada e valorizada na "zona" de prostituição da Vila Mimosa. Embora reconheça a "morte" do malandro, observa que as prostitutas dali costumam ter envolvimento afetivo com homens que carregam traços desta figura, que são aqueles que transitam pela "zona”, bebendo e jogando e que buscam seduzir as prostitutas em busca de relacionamento amoroso ou sexual, mas sem fazer uso da violência. São tidos como companheiros e pessoas carinhosas e mantém relações cordiais com os outros personagens dali, sendo ajudados financeiramente, às vezes, pelas prostitutas com quem se relacionam. A autora considera também que o fascínio ali despertado pela figura do malandro se devia a um encantamento com a postura transgressora a que é associado.

É possível, também, interpretar a aproximação entre a "malandragem" e o mundo da prostituição como fruto da própria configuração que esta assume em nossa sociedade. Perlongher (1987), por exemplo, considera a michetagem como uma recusa à ordem formal relacionada à disciplina do trabalho - e não somente como uma impossibilidade de acesso ao trabalho devida ao desemprego. Tal interpretação é muito próxima das considerações clássicas que são feitas em relação à malandragem. Pode-se pensar, assim, que o malandro não tem apenas proximidade geográfica com o universo da prostituição dos michês, mas que, mais do que isso, se torna uma figura incorporada por eles.

Da Matta (1983) associa, como vimos, o bandido à ilegalidade e o malandro a alguém que vive entre os espaços da legalidade e da ilegalidade. Se refletirmos nestes termos sobre os 
espaços que os profissionais do sexo ocupam nas últimas décadas na sociedade brasileira, podemos associá-los aos mesmos ocupados pelo malandro na proposta deste autor. Na medida em que a prostituição não é considerada um crime, mas também não é uma atividade legalizada, isso a deixa exatamente nessa brecha entre os mundos da legalidade e da ilegalidade - ou, nos termos de Cândido (1993), da ordem e da desordem. Ser, em alguma medida, "malandro", no mundo da prostituição, parece se fazer necessário, principalmente se considerarmos que a figura do cafetão (por vezes associada ao "malandro") está em decadência na prostituição feminina e é praticamente inexistente na masculina. Sem proteção jurídica, devido ao não-reconhecimento legal de sua profissão, e sem ninguém para lhes "proteger", cabe, muitas vezes, às próprias prostitutas, michês e travestis a busca de recursos para conseguirem se posicionar de forma não-submissa em seu meio.

A incorporação da figura do "malandro" era perceptível na relação que as travestis investigadas estabeleciam com seus clientes. A oposição entre o "malandro" e o "otário" descrita por Misse (1999) como a figura complementar à do malandro - parece descrever de forma bastante próxima a relação estabelecida, muitas vezes, entre elas e seus clientes. A busca pelos diversos "truques" e estratégias para enganá-los era objeto freqüente de conversas nos encontros, usualmente com elas se vangloriando de suas ações e rindo dos clientes "otários".

Entre as estratégias utilizadas por elas para aumentar os ganhos no "programa" estava a de cobrar menos para atrair o cliente para uma atividade sexual específica (por exemplo, sexo oral) e depois seduzi-lo para outra modalidade de relação (por exemplo, sexo anal). Como o acordo financeiro não era feito de antemão, isso lhes permitia cobrar um valor muito maior do que o usual. Outro recurso utilizado para ludibriá-los era o de simulação da introdução do pênis no ânus do cliente, quando da impossibilidade da ereção, o que era na verdade feito com os dedos. Se tal "truque" não fosse possível, a travesti comumente o acusava de ser pouco atrativo sexualmente e cobrava o valor integral estipulado anteriormente. $\mathrm{O}$ recurso de urinar no ânus do cliente para simular uma ejaculação também era referido por algumas.

A tentativa por parte dos clientes de inverter essa relação de domínio era sempre punida. Se furtos ou roubos de clientes eram condenados por algumas delas, todas concordavam com algum tipo de punição financeira àquele que tentasse enganá-las - ou seja, em hipótese alguma era permitido fazê-las de "otárias". Um episódio recorrente a esse respeito era o do cliente que pedia um "desconto" pelo programa, referindo não ter dinheiro suficiente para pagar a quantia sugerida, e que depois mostrava ter na carteira a quantia inicialmente solicitada. A punição nesse caso era quase sempre a totalidade do dinheiro possuído.

As estratégias utilizadas para manter os clientes na posição de dominados podem ser classificadas em duas modalidades, que freqüentemente se somavam: o "escândalo" e o uso da força física. Comum também na prostituição de rua feminina, como mostram Gaspar (1986) e Freitas (1985), o escândalo é uma alternativa de controle frente à possível violência do cliente. Gaspar (1996) relaciona esse procedimento às teses de Goffman (1982), para quem os grupos estigmatizados freqüentemente tentam tirar proveito das acusações de que são vítimas. Nesse caso há a manipulação da própria identidade deteriorada: chamando atenção para si, expõe-se o cliente, muitas vezes envergonhado com a situação, constrangendo-o a pagar um "resgate".

Entre as travestis estudadas, o "escândalo" era uma estratégia comum, devido ao receio freqüente dos clientes em serem identificados como homossexuais e/ou clientes de travestis. As ameaças mais freqüentes delas eram a de chamar a polícia ou de anotar o número da placa do carro - nesse caso diziam ter um amigo no Detran que lhes conseguiria seu endereço e ameaçavam mandar uma carta para sua casa, "contando tudo". As travestis identificavam os clientes com aspecto mais "assustado" e utilizavam-se disso como uma estratégia para aumentar os ganhos com o programa, cobrando a mais pela demora no ato sexual ou pela sua repetição e "multando-os" por terem procurado outra travesti ou por alguma observação considerada indevida: 
Um dos assuntos discutidos hoje foi o dos truques para se conseguir mais dinheiro dos clientes. P. contou que um cliente na noite anterior tinha comentado do tamanho de sua "neca" [pênis] e ela disse para ele que ele não podia fazer um comentário daqueles para uma "menina" como ela e que por isso ele ia ter um castigo - pagar $\mathrm{R} \$ 20,00$ a mais. Todas riram da história e várias contaram episódios onde os clientes apareceram sempre no lugar de "trouxas".

Quando à estratégia do escândalo não era suficiente, algumas lançavam mão de ameaças físicas, às vezes brigando de fato com eles. Não era nem um pouco incomum alguma delas aparecer no Grupo com alguma marca no corpo, fruto de algum enfrentamento desse tipo. Embora saíssem por vezes machucadas, referiam-se a estes clientes positivamente, por não terem tido se submetido a elas, o que corresponderia, portanto, a uma postura mais "máscula" da parte deles:

P. estava com a região de um dos olhos bastante inchada. Contou que tinha tentado tirara "um dinheiro a mais" de um cliente, ameaçando-o levar à delegacia e este a enfrentou: "Vamos agora", se encaminhando até uma delegacia próxima. P. virou a direção do carro, quase fazendo ele se chocar com um poste. O cliente parou o carro e ambos se atracaram. Ela foi espancada, mas conta que também conseguiu feri-lo com as unhas. Disse para as outras integrantes que pensou que ia ser fácil, que "ele era magrinho", mas que acabou se "dando mal". D. contou um caso onde ela apanhou de um cliente que "também era um homem de verdade".

Um dos elementos que chamam a atenção em relação à identidade do malandro é que ela se coloca entre as identidades pertencentes ao campo da masculinidade em nossa cultura. Se a identidade do "viado" é considerada como pouco masculina, a do malandro não. A associação do malandro com a masculinidade não se dá em termos somente de sua violência potencial ou real, uma vez que, como vimos, o malandro não é representado como uma figura eminentemente violenta. Tal associação parece se fazer mais em função do lugar de dominador que o malandro estabelece em relação a suas figuras complementares: a "mulher de malandro" e o "otário". Assim, se na relação com seus companheiros fixos ("maridos") as travestis do Grupo se colocavam em uma posição feminina submissa, que se aproximava da de "mulher de malandro", na prostituição, assumiam freqüentemente a do próprio malandro, deixando o cliente nesse lugar submisso.

\section{A relação com a polícia}

A história da homossexualidade, a partir do século XIX, é marcada pelas concepções médicas e jurídicas, que a consideravam ao mesmo tempo uma doença e uma conduta condenável, passível de punição. Realidade comum ao mundo ocidental, esta situação não era diferente no caso brasileiro. Historiadores da homossexualidade no Brasil, como Trevisan (2000) e Green (2000) descrevem longamente a perseguição aos homossexuais ocorrida, em especial àqueles considerados mais femininos. Se a sodomia foi descriminalizada desde o Código Penal Imperial de 1830, tentativas constantes foram feitas, durante toda a primeira metade do século XX, para incluir a homossexualidade como algo, por si só, passível de punição (Green, 2000). Embora tais tentativas não tenham se concretizado, mostram que a homossexualidade permaneceu no limite de ser considerada uma conduta criminosa, o que facilitava a prisão de indivíduos com práticas homoeróticas sob diversas acusações, principalmente o conhecido "atentado ao pudor". Quando escapava da prisão, não era raro um homossexual acabar por ser internado em hospitais psiquiátricos, às vezes a pedido da própria família, como mostra Cunha (1986). 
Realidade semelhante foi vivida pelas prostitutas na história brasileira. Rago (1991), mostra que no período de 1890 a 1930 eram comuns as referências de criminologistas, médicos e policiais à criminologia de Lombroso, que associava a prostituição e a criminalidade, de forma a estabelecer uma identidade entre as mesmas. A alternância de períodos de maior repressão policial à prostituição com períodos de maior tolerância, como o atual, não significa que esta associação não continue presente no imaginário social, uma vez que até hoje "subterfúgios legais, tais como o atentado ao pudor ou o escândalo público, têm sido utilizados como álibis para o enquadramento legal do exercício da prostituição", como mostram Guimarães e Merchán-Hammann (2005, p. 526), em sua análise da prostituição feminina em diferentes cidades brasileiras.

Não é difícil imaginar a violência policial a que foram submetidas as travestis desde seu surgimento como grupo social, no universo da prostituição. Simultaneamente "bichas" e "putas", passaram a ser um alvo privilegiado de contenção por parte dos agentes da ordem. Tal modalidade de violência (ao lado de várias outras, onipresentes em seu cotidiano) pode ser entendida como uma recusa da participação das travestis no espaço público de negociação. Zaluar (2004), observando a multiplicidade de definições dadas ao conceito de violência, na produção de diversos cientistas sociais, considera que:

em todas elas ressalta-se, explicitamente ou não, o pouco espaço existente para que se manifeste o sujeito da argumentação, da negociação ou da demanda, enclausurado que fica na exibição da força física pelo seu oponente ou esmagado pela arbitrariedade dos poderosos que se negam ao diálogo (p. 239).

Se não há o seu reconhecimento enquanto sujeitos, pelo próprio fato de não ocuparem um local definido nos "catálogos" identitários reconhecidos na sociedade brasileira, torna-se evidentemente difícil sua inclusão como um segmento significativo nesse espaço público. Caso aproximemos, aparadas algumas arestas, o conceito de "espaço público" do de "mundo da ordem", visto anteriormente, fica claro que só resta às travestis ocupar os interstícios, vivendo entre o mundo da ordem e da desordem, como ocorre na prostituição e na "malandragem", ou, então, mergulhar de vez no mundo da desordem, da criminalidade, que é o que de fato ocorria muitas vezes entre as travestis pesquisadas, tema ao qual voltaremos mais adiante.

Os policiais (ou "alibãs", na linguagem do Grupo) eram vistos pelas travestis estudadas de uma forma matizada. Se em períodos históricos anteriores a relação deles para com elas era de repressão pura e simples ${ }^{5}$, mais recentemente alguns policiais - denominados "do "bem", em seu discurso - passaram a estabelecer outras modalidades de relações para com elas. Estes mantinham um relacionamento mais próximo, muitas vezes também sexual, e limitavam sua ação a coibir o que elas mesmas consideravam "abuso", como a nudez excessiva, a venda de drogas e os roubos e furtos. Muitos destes costumavam avisá-las de alguma "batida" que fosse ocorrer em algum ponto de prostituição.

Por outro lado, os policiais "do mal" eram descritos como aqueles que acharcavam as travestis, com interesses econômicos, e associavam a ação policial à transfobia, se utilizando de métodos violentos de repressão. Alguns episódios de violência policial por elas descrito se configuravam como práticas de tortura:

As travestis estavam revoltadas com uma batida policial na região da [...] Várias foram levadas de camburão para a Delegacia. A e F contaram que foram levadas para a Serra da Cantareira e deixadas nuas, no meio da estrada, depois de terem sido humilhadas de várias

5 O período do final dos anos 70, recordado por algumas travestis mais velhas do Grupo, foi um momento de especial perseguição policial a elas, na região central de São Paulo. Coordenadas pelo delegado Richetti, as ações tinham como proposta assumida o confinamento e proibição ao trottoir de prostitutas e travestis, como mostram Perlongher (1987) e Trevisan (2000). Sua figura aparecia como a encarnação da violência policial no discurso delas no Grupo, direcionado às travestis mais jovens, quando estas se queixavam da mesma: "Vocês não sabem como era na época do Richetti!". 
formas. A. disse que no caminho foi obrigada a fazer sexo oral como um morador de rua enquanto os policiais riam. Muitas histórias passadas de perseguição policial foram retomadas, entre elas algumas que sugeriam um interesse erótico dos policiais pelas travestis, em situações que misturavam violência e maus-tratos com demandas de ordem sexual por parte dos mesmos, em serem “chupados' ou até mesmo penetrados por elas.

Em seu estudo a respeito da violência contra homossexuais em São Paulo, Spagnol (2001) dedica grande parte de suas descrições à violência de policiais direcionada a travestis. Alguns dados mostram de forma clara a transfobia entre eles. Da frase de um comandante da PM, "se eu pudesse, mataria todos!" (p. 36) às descrições das blitzs como "limpeza" (p. 36 e p. 38), das estratégias de pressão aos clientes, pela anotação das placas dos automóveis (p. 39) à descrição do caso de um policial assassino serial de travestis (pp. 143-164), o autor deixa claro que a violência policial parece não ser exceção, mas sim a regra no trato com tal segmento da população.

\section{Atividades ilícitas}

O recurso a roubos e furtos por parte de travestis é um assunto pouco discutido nos estudos sobre esse segmento ${ }^{6}$. As travestis do Grupo referiam, contudo, que estes eram comuns em praticamente todas as grandes cidades brasileiras, conseqüência do processo de pauperização pelo qual muitas passavam. Isoladas de outros grupos sociais, sem relações de apoio, sem reservas financeiras adequadas para os períodos de menores ganhos, se utilizavam freqüentemente dessa estratégia para possibilitar a satisfação, na maior parte das vezes, de necessidades imediatas, como alimentação e moradia.

As modalidades de roubo e furto de clientes mais comuns entre elas eram três, denominadas de "beijo", "grude" e "puxar a chave". Além dessas, utilizavam alguns golpes, como algumas variações do "suador" (que envolvia o furto do cliente por outra pessoa, durante a relação sexual) e do "boa noite cinderela" - que implicava em fazer o cliente ingerir algo que o fazia dormir (ou o deixava sem poder de reação, como no caso da alcoolização excessiva), enquanto ele era furtado.

O "beijo" envolvia o furto de dinheiro ou cartões de crédito ou bancários do cliente. Era feito durante o ato sexual propriamente dito, geralmente no próprio carro do cliente, em drive-ins, momento no qual a travesti vasculhava sua carteira nos bolsos, debaixo do banco do carro ou em outros esconderijos comuns. "Beijar" era considerado por algumas delas uma "arte", pois implicava em grande habilidade, para o cliente não perceber o furto:

P. [travesti muito frequente no Grupo, especialista em "beijo"] disse que nunca havia sido "pega". Disse a ela que duvidava de tanta habilidade. No meio do encontro várias travestis começaram a rir e perguntei os motivos. P., que estava sentada duas cadeiras à minha direita, mostrou minha carteira, que tinha pego em minha bolsa, a qual tinha ficado o tempo todo do meu lado. Fiquei surpreso com sua rapidez.

Para garantir o sucesso da operação e ainda ganhar um extra, a travesti, depois do "beijo", costumeiramente dava uma bronca enorme no cliente quando este se percebia sem dinheiro, na hora do pagamento do "programa". Exigia que o mesmo fosse sacar dinheiro em algum posto bancário ou que voltasse para pagar no dia seguinte. A bronca nesse caso parecia servir para desconcertá-lo, fazendo-o pensar que havia perdido o dinheiro ou tivesse sido furtado em outro local.

6 É abordado somente por Kulick (1998), entre as travestis de Salvador, e por Ferreira (2003), entre as de Belém. 
Outra modalidade muito utilizada era o "grude" . Ele correspondia, entre elas, à utilização dos mesmos mecanismos de "escândalo" e de ameaça de uso da força física citados anteriormente. Nesse caso, porém, não eram estratégias para se conseguir um pagamento considerado adequado, mas sim para se roubar alguém. O "grude" era, em função de seu objetivo, claramente diferenciado, por elas, do castigo financeiro considerado merecido, impingido ao cliente que as humilhava, solicitando descontos, por exemplo. Podia envolver alguém que havia pago pelo programa a quantia combinada ou que ainda estava negociando o preço de um programa. Uma estratégia comum para "grudar" era a de se pedir uma "carona" e ameaçar a pessoa no caminho.

Como envolvia um enfrentamento direto com o (possível) cliente, o "grude" envolvia riscos maiores, principalmente se este estivesse armado. Algumas travestis pesquisadas não "grudavam" (ou o faziam raramente) em função do medo da reação que poderia provocar. Para "grudar", consideravam que a travesti deveria ser corajosa:

$\mathrm{Na}$ discussão [sobre o consumo excessivo de álcool] B. contou que só bebia excessivamente às terças-feiras. Achei estranho tal padrão de consumo. Mais tarde revelou os motivos da preferência por este dia: era seu dia de "grudar" e o álcool era necessário para lhe dar a coragem que precisava.

A terceira modalidade entre as mais utilizadas era a de "puxar a chave". Tal prática envolvia uma aproximação do automóvel do (possível) cliente pelo lado do passageiro e um "mergulho" rápido para retirar a chave do contato. A chave só era entregue mediante certo pagamento, que aquele quase sempre fazia, por medo de ser agredido ou ter seu carro amassado ou riscado, o que era comumente feito se o pagamento não fosse efetuado. A exemplo das outras modalidades, o "puxar a chave" envolvia uma técnica precisa:

\begin{abstract}
V. contou no Grupo que tinha tentado "puxar a chave" do carro de um cliente e que não conseguiu tirá-la. O cliente riu de sua falta de jeito e V. disse que ficou envergonhada e que nunca mais tentaria fazê-lo de novo. Várias travestis riram e P. lhe deu dicas de como deveria girar a chave. A. falou, porém, de alguns modelos de carro que tinham mecanismo diferentes.
\end{abstract}

Da mesma forma que o dinheiro ganho com a prostituição, o obtido com os roubos e furtos era também considerado um dinheiro "maldito", que "entrava e saia fácil", o que as mantinha na necessidade de novos "golpes", mesmo quando conseguiam uma quantia elevada em alguma destas ocasiões. Zaluar (2004) observa tal representação do dinheiro também entre "bandidos" cariocas, que justificavam desta forma a necessidade constante de continuar praticando atos ilícitos.

Quando percebiam que o cliente era potencialmente agressivo, as travestis evitavam durante certo período freqüentar o mesmo ponto de prostituição e migravam para outros. Outras faziam o processo inverso: buscavam pontos distintos para roubar, mantendo o seu para a prostituição. Obviamente isso só poderia ser feito em metrópoles que tem várias regiões de prostituição travesti. Mas mesmo nestas, elas podiam ficar visadas após algum tempo, tornando necessária a mudança para outra cidade. Este é um os fatores que explicam a constante migração de travestis pelas grandes cidades brasileiras.

A resposta aos roubos e furtos era algumas vezes bastante violenta. Eram comuns as histórias de clientes que voltavam armados procurando as travestis de que foram vítimas:

Hoje todas estavam assustadas. Contaram que havia uma carro preto suspeito circulando pela Av. [...] e que achavam que estavam procurando por alguma travesti da área, segundo o que uma outra travesti teria comentado. Achavam provável que fosse um cliente que

7 Citado também, a exemplo do "beijo", por Kulick (1998). 
tinha sido roubado por alguma delas e que veio para "acertá-la".

Hoje o assunto foi o assassinato de P. [travesti que já tinha vindo ao Grupo uma ou duas vezes]. Segundo elas, P. foi morta por engano, confundida com outra travesti loira. Acham que o assassino não achou a outra e acabou matando-a "para não perder a viagem", porque ambas eram muito diferentes.

A violência dos clientes era bem mais temida do que a policial, em virtude de ser muitas vezes mortal. Se era vista como uma resposta dos clientes a pequenos golpes, roubos e furtos por parte delas próprias, o grau de violência empregado e o desejo de humilhação das travestis implícito nos atos sugeria também a transfobia já referida. Os inúmeros assassinatos de travestis no Brasil, quase todos sem investigação e punição dos responsáveis, são extensamente discutidos por Mott (2000).

Um outro fator importante que aproximava as travestis de baixa renda estudadas das atividades ilegais era o (ab) uso de substâncias psicoativas, especialmente a "pedra". Elas eram unânimes em afirmar que a disseminação do crack em São Paulo, na década de 90, foi um fator importante para o aumento dos roubos direcionados aos clientes. Aquelas que faziam uso constante do crack, que não eram poucas, estavam quase sempre entre as que mais "beijavam", "grudavam" ou "puxavam a chave". O dinheiro obtido dessa forma era quase sempre revertido todo para a compra do produto, mantendo-as em uma situação de penúria econômica. Tais travestis eram referidas como "nóias" ou "noiadas", termo comum para os usuários de crack em São Paulo.

Se em relação ao álcool ou à maconha, de uso freqüente entre elas, não havia sinais de dependência visíveis, o mesmo não se pode dizer do crack. Algumas mostravam sinais claros de abstinência do uso - a chamada "fissura". A própria discussão do assunto levava muitas a manifestá-la, pela imitação freqüente do gesto do consumo - acendendo imaginariamente um cachimbo com um isqueiro, aspirando fortemente o ar. ${ }^{8}$

O ab(uso) do crack fazia com que algumas delas passassem a vendê-lo ou repassá-lo (como "avião") aos clientes ou outros usuários. Essa era uma estratégia que lhes permitia utilizar parte das "pedras" adquiridas:

T. contou que no dia anterior uma pessoa solicitou a ela que fosse comprar duas pedras de 10 [as pedras maiores custavam 10 reais]. Ela pegou o dinheiro, comprou as duas e as dividiu, ficando com duas para ela.

A instituição em que o Grupo se reunia ficava próxima à área conhecida como "Crackolândia", na região central de São Paulo, que mais recentemente tem sido alvo de políticas públicas no sentido de revitalizá-la. Por congregar simultaneamente um mercado de prostituição, possibilitado pela presença de inúmeros hotéis baratos, e o comércio do crack e outras substâncias psicoativas, tal área permitia um envolvimento muito próximo de várias travestis com estas substâncias. Por medo da repressão policial, muitos hotéis proibiam a presença de clientes desacompanhados por um período curto de tempo, em virtude da desconfiança em relação ao provável uso do crack. Isso fazia com que muitos usuários buscassem travestis ou prostitutas como "acompanhantes", tendo o intuito simultâneo ou exclusivo de fumar crack. Algumas travestis referiram ter sido este mecanismo que as levou à dependência deste. Esse mesmo processo fez outras entrarem diretamente para o tráfico, passando a oferecer e vender as "pedras" aos usuários.

\footnotetext{
$8 \mathrm{Um}$ dos aspectos que as incomodava particularmente em relação ao crack era em relação ao emagrecimento que este gera com o uso contínuo, em função de um de seus efeitos mais comuns ser a perda do apetite. A busca por um corpo mais feminino entre elas estava associada a ter formas corporais mais volumosas e era impossibilitada pelo emagrecimento.
} 


\section{Incriminação}

Era significativo o número de travestis do Grupo já condenadas por algum tipo de delito e que haviam cumprido pena. Além disso, quase todas já havia sido detida por um ou alguns poucos dias, sob a freqüente acusação de "atentado ao pudor". Lugares quase esquecidos nos estudos sobre travestis, as delegacias e prisões tinham um lugar relevante, porém, na socialização e constituição identitária das travestis investigadas.

A detenção temporária, motivada na maior parte das vezes pela reclamação de moradores, em virtude de atos considerados obscenos, envolvia o pernoite em alguma delegacia, com a liberação da travesti no dia seguinte. Entre elas, de tão comum, tal prática era referida como "dormir na delegacia". Nas noites passadas em delegacias, era comum que realizassem algum "programa" com outra pessoa detida. Havia, porém, a possibilidade de abuso sexual por parte dos outros presos, principalmente se a travesti estivesse presa sem a companhia de outras. Tal possibilidade era utilizada como simples castigo por parte de policiais ou como instrumento de pressão, uma vez que, por serem personagens "da noite", as travestis eram consideradas boas informantes por eles, o que fazia com que fossem pressionadas para delatar suspeitos de terem realizado algum crime. Não eram incomuns outras estratégias com a mesma finalidade, como obrigá-las a fazer a faxina da delegacia e ameaçá-las a "assinar o artigo".

"Assinar o artigo", isto é, a acusação formal por ato obsceno ou por outro motivo era algo bastante temido por elas. Se nas delegacias havia maus-tratos, estes eram referidos como menos intensos do que os ocorridos no final da década de 70 e na década de 80 , segundo as mais velhas que freqüentavam os encontros. Além disso, configurava-se como uma situação transitória, diferentemente da condenação por algum crime, que as levava às instituições penitenciárias.

Aquelas que já haviam cumprido pena privativa de liberdade tinham más recordações dos presídios pelos quais passaram. Embora pareça haver muita diferença entre eles, em relação ao grau de aceitação de travestis, no geral elas eram submetidas a diversas formas de discriminação nos presídios, por parte de agentes penitenciários e de outros presos.

J e D. foram visitar A. na Cadeia de Pinheiros [que havia sido presa por tentativa de assalto alguns meses antes]. Disseram que ela estava com o cabelo curso e estava triste com isso. A. contou a elas que estava "dando mais que chuchu na cerca" para se virar na prisão e que pediu aos funcionários para que tentassem mudá-la de local.

Welzer-Lang (2001) considera que as prisões reproduzem a imagem hierarquizada das relações entre homens e mulheres, o que pode ser observado na forma como alguns segmentos de homens (considerados mais femininos) são tratados por outros (tidos como mais masculinos) o que faz com que

os jovens homens, os homens localizados ou designados como homossexuais (homens ditos efeminados, travestis...), homens que se recusam a lutar, ou também os que estupraram as mulheres, dominadas, são tratados como mulheres, violentados sexualmente pelos "grandes homens" que são os chefões do tráfico, roubados, violentados. Freqüentemente, eles são apenas colocados na posição da "empregada" e devem assumir o serviço daqueles que os controlam, particularmente o trabalho doméstico (limpeza da célula, da roupa...) e os serviços sexuais.

9 As travestis se referiam como "atentado ao pudor" qualquer ato considerado obsceno, como, por exemplo, nudez excessiva. No Código Penal, porém, essa possibilidade consta do artigo 233 (que se refere ao "ato obsceno") e que difere do "atentado violento ao pudor" - artigo 214, que se refere aos atos que envolvem violência ou grave ameaça a alguém com objetivos sexuais (exceto estupro). 
Tal descrição parece corresponder em certa medida à realizada pelas travestis do Grupo que já haviam sido presas. Mas a submissão delas não era total como a citação sugere, uma vez que, quando juntas, podiam estabelecer espaços de resistência frente aos vários segmentos da população carcerária. Essa contradição é explicitada em duas obras voltadas à descrição do Complexo Penitenciário do Carandiru. Varella (2003) observa que ali elas ocupavam um lugar específico na hierarquia entre os diferentes segmentos de presidiários, uma vez que não era tolerado que cometessem atos violentos relacionados aos bandidos "homens". Ao mesmo tempo, refere que eram identificadas como perigosas pelos outros presos, independentemente do que tivessem feito. O documentário "O Prisioneiro da Grade de Ferro", realizado por presidiários do mesmo Complexo, mostra a mesma ambivalência. A travesti que narra a filmagem da "Rua das Flores", local que concentrava parte das travestis dali, relata: "Nós que somos bichas não pode quase nada. Quem pode é só os homens. Nós pode ficar quietinha, ficar quieta no lugar da gente". Ao mesmo tempo, porém, cita que a restrição geográfica a que as travestis eram submetidas se devia às brigas que causavam em outros setores da penitenciária, o que mostra que não há uma submissão total por parte delas, que reagem muitas vezes ativamente à violência sofrida.

Algumas lideranças que defendem a legalização da prostituição buscam separar tal atividade das atividades ilícitas, nas quais os segmentos que representam às vezes se envolvem. Isso também ocorria no Grupo, onde algumas travestis que se opunham aos roubos e furtos referiam-se à prática exclusiva da prostituição, somada a eventuais "castigos" aos clientes que as humilhavam, como "trabalhar na moral". Buscavam, nestes termos, se diferenciar das que roubavam e as criticavam abertamente nos encontros, gerando tensão entre elas. É evidente que do ponto de vista político essa distinção se faz necessária, uma vez que é mais provável (ainda que difícil) o apoio da opinião pública à prostituição do que aos roubos e furtos. No caso das travestis investigadas, contudo, tal defesa não pode obscurecer o fato de que há uma proximidade histórica entre os "mundos" da prostituição, da homossexualidade e do crime, associação esta facilitada pelo estigma relacionado a todos eles, que acaba por influir na constituição identitária deste segmento.

Além da questão financeira, outros elementos podem estar presentes na associação entre criminalidade e prostituição, ao menos na masculina. Perlongher (1987), em seu estudo sobre michês paulistanos na década de 80 , interpreta os roubos de clientes por parte deles como motivados não só pela necessidade financeira imediata, mas também como uma maneira de extravasar a raiva em relação à situação de penúria, algo explícito na relação com clientes de maior poder aquisitivo. Observa que também são conseqüência da destruição de laços de solidariedade territorial entre os diversos segmentos que ocupam os mesmos espaços, fazendo com que os relacionamentos passem a ser cada vez mais anônimos.

A conjunção entre a prostituição masculina e a criminalidade é também facilitada pela superposição dos territórios da homossexualidade e da criminalidade em algumas grandes cidades. A base espacial comum da prostituição masculina e criminalidade é citada em relação aos michês por Perlongher (1987), em São Paulo, e às travestis por Silva (1993), no Rio de Janeiro, que considera que bandidos e travestis estão imersos em um mesmo circuito de relações informais.

Se as que "trabalhavam na moral" incorporavam parcialmente as identidades de prostituta e de malandro no campo ocupacional, propomos considerar que as travestis que se envolviam diretamente em atividades ilícitas apropriavam-se também de uma outra identidade nessa esfera: a do bandido. O termo "bandida" era, de fato, usado algumas vezes por elas como referência às travestis que roubavam. A identidade do "bandido" parece ser parcialmente incorporada não somente pela prática em comum (roubar), como também pela convivência próxima que muitas tinham com bandidos. A convivência dava-se nos relacionamentos com "maridos" que eram bandidos, no relacionamento cotidiano com traficantes ou ladróes, que às 
vezes as ajudavam em roubos a clientes potenciais e, como vimos, nas vivências no sistema prisional.

Adorno (1991) propõe considerar que as respostas institucionais a comportamentos desviantes, como as práticas prisionais, resultam na elaboração de identidade e carreiras criminosas. A reincidência criminal, para o autor, mostra que a separação entre "trabalhadores" e "bandidos" e é facilitada pela especialização na prática do crime. Misse (1999, p. 41) denomina tal processo "sujeição criminal" e considera que as representações de "mundo" ou "submundo do crime" se apóiam na noção de "bandido", que passa a ser alguém diferenciado de outros tipos sociais. $\mathrm{O}$ controle desse submundo exige a demarcação de quem faz parte dele, o que produz a sujeição criminal - passam a haver subjetividades que incorporam a incriminação a elas direcionada, agindo "como se, de algum modo, capturassem a sua definição social, assumindo-a e desenvolvendo-a como sua própria definição" (p. 47). A transgressão "desliza" para a subjetividade do agressor e passa a ser entendida como algo inerente a ele, como seu caráter, formando a identidade de "bandido".

Se a identidade de bandido é resultado tanto de atribuição social quanto de sua incorporação, como encarar tal processo entre travestis? Nossa hipótese é de que as travestis tenham progressivamente incorporado a incriminação a que foram historicamente submetidas. Embora tal possibilidade implique em um estudo específico sobre o tema, sua plausibilidade ocorreu-me em uma visita ao "Museu do Crime", na cidade de São Paulo. Lá, em uma sala denominada "Medicina Legal", há a foto de uma travesti sem qualquer referência ao crime cometido, o que diferia das demais fotos e objetos, que se referiam a suicídios, homicídios, abortos e infanticídios, dentre outros. Ou seja, a travesti estava lá pelo simples fato de ser travesti, o que sugere que elas são objeto de incriminação social pelo simples fato de excederem as classificações normativas associadas ao gênero e sexualidade presentes em nossa sociedade.

Outro fato a se considerar é a relação que elas próprias estabeleciam com bandidos. Misse (1999, p. 65), ao falar da sujeição criminal, considera-a como uma "potencialidade de todos os indivíduos que possuam atributos próximos ou afins ao tipo social acusado". Isso equivale a dizer que se há o tipo "ideal" do bandido, há os que dele se aproximam em maior ou menor grau. Para o autor, há uma ampliação da sujeição criminal para os indivíduos e grupos que mantém relações regulares com os que se encontram socialmente sob "exclusão criminal", mas que não são considerados bandidos.

$\mathrm{Na}$ configuração de sua identidade, para o mesmo autor, os "bandidos" passam a valorizar positivamente a identidade a eles atribuída, originalmente negativa. Tal positivação da identidade pode ser percebida, para ele, nas "narrativas de trajetórias, peripécias e façanhas" dos sujeitos criminais (Misse, 1999, p. 202). Tais narrativas podiam ser observadas entre as travestis pesquisadas, envoltas na demonstração de orgulho pelas habilidades e nos relatos um tanto ostentosos dos golpes aplicados. Aquelas que roubavam chegavam a exibir certo desprezo em relação às que "trabalhavam na moral", o que era interpretado como falta de coragem - e não como algo fruto de uma postura mais ética.

Os bandidos eram considerados sexualmente desejáveis pelas travestis do Grupo, que fazia com que fossem "maridos" ou "vícios" (parceiros ocasionais) preferenciais. Tal desejo parecia estar relacionado à representação por parte deles de uma masculinidade associada à violência, comum em alguns segmentos populares. Se a hiper-masculinidade associada ao bandido era algo desejável, a apropriação da mesma identidade pelas travestis não era isenta de contradições, uma vez que implicava em se colocar em uma posição eminentemente masculina, algo contraditório em um grupo que em outras modalidades de interação busca por um lugar feminino. 


\section{Conclusão}

Observamos neste artigo que a prostituição tornou-se, por motivos históricos, um elemento definidor da identidade das travestis. Nesse sentido, consideramos que esta identidade ultrapassou o campo das identidades sexuais ou de gênero, se tornando também uma identidade profissional. É evidente que não podemos reificar a associação entre travestis e prostituição, mas ao mesmo tempo não podemos deixar de considerar que a ocupação deste campo de trabalho pelas travestis acabou por ter conseqüências importantes sobre sua constituição identitária.

Consideramos que a ocupação deste campo profissional, entre as travestis de baixa renda estudadas, levou-as à incorporação da identidade da "puta" em sua "colcha de retalhos" identitária, o que se deu em função da atividade em comum, da contigüidade espacial, da convivência com prostitutas mulheres e do desejo de atrair sexualmente os homens - o que evidenciaria a própria feminilidade. Na relação que estabeleciam com seus clientes, vistos de forma heterogênea, a identidade de "puta", contudo, não era a única relevante. A busca por um lugar de domínio frente aos clientes, por meio de estratégias como o escândalo e a ameaça do uso da força física, combinados aos "truques" da profissão, sugeriam a assimilação por parte delas de outra identidade, a do "malandro", deixando os clientes na posição complementar, a de "otários".

Em relação às atividades ilícitas, consideramos que as travestis estudadas incorporaram a incriminação a que foram submetidas historicamente. Pela falta de perspectiva profissional e pelos recursos muitas vezes insuficientes vindos da prostituição, vimos que muitas das travestis investigadas passaram a recorrer aos roubos e furtos como estratégia de ganhos financeiros. Descrevemos as três modalidades mais praticadas - o "beijo", o "grude" e o "puxar a chave" -, observando que tais práticas contribuíam para o aumento da violência direcionada a elas como grupo social.

Refletimos também sobre a importância de considerar o relacionamento com os bandidos e as vivências no sistema prisional como elementos importantes na socialização das travestis pesquisadas. A prática de delitos e o tráfico de drogas - no qual várias se envolviam para sustentar o próprio consumo, especialmente de crack - fazia com que se aproximassem ainda mais do "mundo do crime", o que possibilitava a incorporação de outra identidade em sua constituição identitária: a do "bandido".

O presente estudo mostra de forma clara a necessidade de uma atenção ao mercado da prostituição e a seus mecanismos de exclusão. Consideramos que a falta de legalização da profissão e o estigma associado a esta prática leva contingentes significativos de profissionais do sexo a romperem os limites desta prática profissional e a se envolverem em atividades ilícitas, como roubos e tráfico de drogas, o que se intensifica nos segmentos de baixa renda, como é o caso das travestis estudadas. Ao fazerem isso, acabam por retro-alimentar o processo histórico de incriminação a que foram submetidas em uma sociedade que não tolera aqueles(as) que rompem com as expectativas de gênero hegemônicas. $O$ rompimento com esse círculo vicioso surge, dessa forma, como uma necessidade premente dos estudos e intervenções direcionados a essa população.

\section{Referências}

Adorno, S. (1991). A prisão sob a ótica de seus protagonistas: itinerário de uma pesquisa. Tempo Social, 3 (1-2), $7-40$. 
Benedetti, M. R. (2000). Toda feita: o corpo e o gênero das travestis. Dissertação de Mestrado, Antropologia Social, Universidade Federal do Rio Grande do Sul, Porto Alegre.

Cândido, A. (1993) Dialética da malandragem. In O discurso e a cidade. São Paulo: Duas Cidades.

Clastres, P. (2003) A sociedade contra o Estado: pesquisas de antropologia política. São Paulo: Cosac-Naify.

Cunha, M. C. P. (1986) O espelho do mundo: Juquery, a história de um asilo. Rio de Janeiro: Paz e Terra.

Da Matta, R. (1983). Carnavais, malandros e heróis: para uma sociologia do dilema brasileiro. Rio de Janeiro: Zahar.

Ferreira, R. S. F. (2003). As "bonecas" da pista no horizonte da cidadania: uma jornada no cotidiano travesti. Dissertação de Mestrado, Desenvolvimento Sustentável do Trópico Úmido, Universidade Federal do Pará, Belém.

Freitas, R. S. (1985) Bordel, bordéis: negociando identidades. Petrópolis: Vozes.

Garcia, M. R. V. (2007). "Dragões": gênero, corpo, trabalho e violência na formação da identidade entre travestis de baixa renda. Tese de Doutorado, Instituto de Psicologia, Universidade de São Paulo, São Paulo.

Garcia, M. R. V. (2008). Care of the body among low-income travestis. Sexualidades: a working paper series on Latin American and Caribbean Sexualities, 2, 1-15.

Gaspar, M. D. (1985). Garotas de programa: prostituição em Copacabana e identidade social. Rio de Janeiro: Zahar.

Goffman, E. (1982). Estigma: notas sobre a manipulação da identidade deteriorada. Rio de Janeiro: Zahar.

Green, J. N. (2000). Além do carnaval: a homossexualidade masculina no Brasil do século XX. São Paulo: Unesp.

Guimarães, K. \& Merchán-Hamann, E. (2005). Comercializando fantasias: a representação social da prostituição, dilemas da profissão e a construção da cidadania. Estudos Feministas, 13 (3), 525-544.

Misse, M. (1999). Malandros, marginais e vagabundos: acumulação social da violência no Rio de Janeiro. Tese de Doutorado, Sociologia, Instituto Universitário de Pesquisas do Rio de Janeiro, Rio de Janeiro.

Moraes, A. F. (1996). Mulheres da Vila. Petrópolis: Vozes.

Mott, L. (2000). Violação dos direitos humanos e assassinato de homossexuais no Brasil. Salvador: GGB.

Parker, R. (1992). Corpos, prazeres e paixões. São Paulo: Best-Seller.

Pelúcio, L. (2005). Sexualidade, gênero e masculinidade no mundo dos T-lovers. Anais do XII Congresso Brasileiro de Sociologia, Belo Horizonte: Sociedade Brasileira de Sociologia.

Perlongher, N. (1987). O negócio do michê: prostituição viril em São Paulo. São Paulo: Brasiliense.

Rago, M. (1991). Os prazeres da noite: prostituição e códigos da sexualidade feminina em São Paulo, 1890-1930. Rio de Janeiro: Paz e Terra.

Silva, H. R. S. (1993). Travesti: a invenção do feminino. Rio de Janeiro: Relume-Dumará.

Spagnol, A. S. (2001). O desejo marginal. São Paulo: Arte \& Ciência.

Trevisan, J. S. (2000). Devassos no paraíso: a homossexualidade no Brasil, da Colônia à atualidade. Rio de Janeiro: Record.

Varella, D. (2003). Estação Carandiru. São Paulo: Companhia das Letras.

Welzer-Lang, D. (1994). Prostitution: les uns, les unes et les autres. Paris: Métailié.

Welzer-Lang, D. (2001). A construção do masculino: dominação das mulheres e homofobia. Estudos Feministas, 9 (2), $460-482$

Zaluar, A. (2004). Integração perversa: pobreza e tráfico de drogas. Rio de Janeiro: FGV.

\author{
Endereço para correspondência \\ mrgarcia@usp.br
}

Recebido em: 14/04/2008

Aprovado em: 21/07/2008 